\title{
Decontamination of respirators in the covid-19 pandemic
}

\section{Miranda Loh head of environment and public health, John W Cherrie principal scientist, Robert J Aitken chief executive}

Institute of Occupational Medicine (IOM), Edinburgh EH9 1AX, UK

We are in a public health crisis, with frontline healthcare workers at increased risk of acquiring covid-19, partly due to shortages in respiratory protection. The respirators normally used to protect healthcare workers should be disposed of frequently, preferably after each patient, but this is currently not possible.

Medical personnel have expressed concern over Public Health England's new guidance recommending that personal protective equipment (PPE) be stretched across a shift or even reused. ${ }^{12}$ Decontamination of respirators could be one way of increasing the safety of reuse and is being actively pursued by various groups.

Some methods require more specialised equipment (such as hydrogen peroxide vapour or ultraviolet light) and might not be as easily accessible in all settings. We have undertaken pilot work with a group of engineers using heat (about $70^{\circ} \mathrm{C}$ for around one hour) to decontaminate respirators while retaining their effectiveness. ${ }^{3}$ This might be a simple method that allows limited reuse of respirators in healthcare settings for the short term, although further tests of the decontamination method are required.
This pandemic has shown that we need to change the way we approach PPE. Widespread use of disposable kit has led to the current shortage and is not sustainable in the long run. We also need effective PPE that comfortably fits a wider range of body and face types.

JWC is also a professor at the Institute of Biological Chemistry, Biophysics and Bioengineering, Heriot Watt University, Edinburgh.

Competing interests: None declared.

Full response at: https://www.bmj.com/content/369/bmj.m1577/rr-1.

Rimmer A. Covid-19: Experts question guidance to reuse PPE. BMJ 2020;369:m1577. 10.1136/bmj.m1577 32312734

2 Public Health England. Considerations for acute personal protective equipment (PPE) shortages. Updated 3 May 2020. https://www.gov.uk/government/publications/wuhannovel-coronavirus-infection-prevention-and-control/managing-shortages-in-personalprotective-equipment-ppe

3 Loh M, Clark R, Cherrie JW. Heat treatment for reuse of disposable respirators during Covid-19 pandemic: Is filtration and fit adversely affected? medRxiv 2020.04.22.20074989. [Preprint]. https://www.medrxiv.org/content/10.1101/2020.04.22.20074989v1

Published by the BMJ Publishing Group Limited. For permission to use (where not already granted under a licence) please go to http://group.bmj.com/group/rights-licensing/ permissions 